\title{
Development of a Nephrotic Syndrome in a Patient with Gastrointestinal Stromal Tumor during a Long-Time Treatment with Sunitinib
}

\author{
Maria Caterina Pallotti ${ }^{a}$ Maria Abbondanza Pantaleo ${ }^{a, b}$ \\ Margherita Nannini ${ }^{a}$ Francesca Centofanti $^{\mathrm{C}}$ \\ Benedetta Fabbrizio ${ }^{d}$ Mara Montanari ${ }^{c}$ Olga Baraldi ${ }^{c}$ \\ Maristella Saponara ${ }^{a}$ Cristian Lolli $^{\mathrm{a}}$ Anna Mandrioli ${ }^{\mathrm{a}}$ \\ Guido Biasco ${ }^{a, b}$ Rita Prandini ${ }^{c}$ \\ ${ }^{a}$ Department Institute of Hematology and Medical Oncology 'L. and \\ A. Seragnoli', S. Orsola-Malpighi Hospital, University of Bologna, \\ 'Interdepartmental Centre for Cancer Research 'G. Prodi', University of \\ Bologna, 'Section of Nephrology, Department of Internal Medicine, Aging and \\ Renal Disease, St. Orsola Hospital, University of Bologna, and ${ }^{d}$ Pathology Unit, \\ Addari Institute of Oncology, S. Orsola-Malpighi Hospital, Bologna, Italy
}

\section{Key Words}

Gastrointestinal stromal tumor - Sunitinib - Nephrotic syndrome - Vascular endothelial growth factor P Proteinuria $\cdot$ Renal toxicity

\begin{abstract}
A patient with advanced gastrointestinal stromal tumor (GIST) receiving second-line treatment with sunitinib developed edema, increase of the serum creatinine, weight gain, nephrotic syndrome with proteinuria of $12 \mathrm{~g} / 24 \mathrm{~h}$, dyslipidemia, hypoalbuminemia and also presented with hypertension. A kidney biopsy showed an immunocomplex glomerulonephritis. Steroid treatment was started, but the clinical conditions and laboratory values did not improve. So in the hypothesis that the nephrotic syndrome was induced by sunitinib, sunitinib was temporarily discontinued with a subsequent reduction of proteinuria and improvement in blood pressure control. In the last years, the introduction of sunitinib has modified the natural history of advanced GIST. However, due to chronic and prolonged intake of this drug, there is increasingly frequent detection of late and unknown toxicities in clinical practice. In particular, the late renal toxicity from sunitinib may be the primary clinical problem with this drug in the case of prolonged treatment. Monitoring of kidney
\end{abstract}


function and blood pressure should be performed for early detection of side effects such as hypertension and kidney dysfunction in advanced GIST patients receiving long-term treatment with sunitinib. A clinical collaboration between oncologists and nephrologists could be useful with the objective to optimize the management of sunitinib.

\section{Introduction}

Gastrointestinal stromal tumors (GISTs) are the most common mesenchymal neoplasms of the gastrointestinal tract. They are derived from the interstitial cells of Cajal (ICC). The stomach is the most frequent site of GISTs (60\%) followed by small bowel $(35 \%)$ and colon-rectum $(<5 \%)$. Esophagus, peritoneum, and retroperitoneum are rare sites [1]. The site of GIST, the mitotic index, and the dimension define the risk of recurrence (high, intermediate, low, or very low). GISTs usually metastasize to the peritoneum and liver, whereas lymph nodes, lung, or bone are seldom involved.

Molecular analysis can show a mutation in the KIT gene (80-95\%), in the plateletderived growth factor alpha (PDGFR- $\alpha$ ) gene (5-7\%) or no mutations (wild type, 10 15\%) [1]. The activation of these tyrosine kinase receptors by signal transduction pathways promotes the cellular cycle activation, cell proliferation, and apoptosis inhibition. Mutation of exon 11 is the most frequent mutation of the KIT gene; other possible mutations are in exon 9, exon 13, and, seldom, in exon 17 [1]. Mutation of PDGFR $\alpha$ can involve exon 12, exon 14 or, in the majority of cases, exon 18 [1].

Surgical resection is the treatment of choice for localized GIST, whereas medical treatment with the selective tyrosine kinase inhibitors (imatinib, sunitinib) are used in patients with localized unresectable or metastatic GIST. Imatinib is the standard firstline therapy for localized unresectable, recurrent or metastatic GIST, and also for the adjuvant treatment for patients with intermediate or high risk of recurrence after surgical resection [2-4]. Sunitinib is approved as second-line therapy when GIST does not respond to imatinib or if there is intolerance to imatinib [5]. KIT and PDGFR $\alpha$ genotype status is predictive of treatment response. Imatinib has demonstrated better tumor response and progression-free survival (PFS) in exon 11 KIT mutation compared with sunitinib having demonstrated longer PFS and clinical benefit in patients with exon 9 KIT mutation and in wild-type genotype [1].

Sunitinib is a multitargeted receptor tyrosine kinase inhibitor as KIT, PDGFR $\alpha$, PDGFR $\beta$, different vascular endothelial growth factor receptors (VEGFR-1,VEGFR-2, VEGFR-3), Fms-like tyrosine kinase-3 receptor (FLT3), and the receptor encoded by the RET protoncogene (RET). Sunitinib has antiangiogenic and antitumor activity. Imatinib and sunitinib bind KIT and PDGFR in different ways so it is possible to obtain tumor response with sunitinib in patients with imatinib-resistant GIST. Sunitinib is an oral drug, metabolized mainly by the cytochrome P450 (CYP 450); fecal excretion is approximately 64\%; renal elimination is approximately $14 \%$. Efficacy and tolerability of sunitinib in GIST is demonstrated in phase 1-2-3 clinical trials and also in an expanded-access study [6].

Initially, the standard dose was $50 \mathrm{mg} /$ day for four weeks followed by two weeks without treatment; alternatively, the dose of $37.5 \mathrm{mg} /$ day continuously without a 
scheduled off-treatment period has the same efficacy and retains the cytostatic effect [7]. More common adverse events are fatigue, gastrointestinal symptoms (diarrhea, nausea, vomiting), hematologic toxicities (anemia, neutropenia, thrombocytopenia), hypertension, skin disorders (yellow skin, hand-foot syndrome), and stomatitis. Occasionally, hypothyroidism can develop and, seldom, hemorrhage of the neoplastic mass [6]. In patients with many adverse events, it is possible to administer a dose reduction (sunitinib $25 \mathrm{mg}$ /day). There are also described in the literature some case reports of development of hypertension, proteinuria, and kidney dysfunction during treatment with sunitinib [8-10]. We describe here the case of nephrotic syndrome in a patient with advanced GIST under treatment with sunitinib.

\section{Case Report}

A 52-year-old man was admitted for ileal resection of a mass discovered in February 2002. Mass biopsy diagnosed GIST. The tumor size was $6.5 \mathrm{~cm}$, the mitotic index was $4 / 50$ high power field s and the immunohistochemical analysis revealed the tumor was positive for CD117, and negative for CD34 and S100. The tumor presented KIT exon 9 mutation (c.1504_1509dup (p.Ala502_Tyr503dup)). At baseline, the patient had a serum creatinine of $0.9 \mathrm{mg} / \mathrm{dl}\left(\mathrm{eGFR} 92.0 \mathrm{ml} / \mathrm{min} / 1.73 \mathrm{~m}^{2}\right)$. Urinalyses were normal and weight was $60.0 \mathrm{~kg}$. In the same period, the patient had taken antihypertensive therapy with ramipril and hydrochlorothiazide.

Follow-up was negative until 2004 when an abdominal echography demonstrated multiple hepatic and omental lesions compatible with metastases. Imatinib $400 \mathrm{mg}$ /day was started and in August 2005, the dose was increased at $800 \mathrm{mg} /$ day for progressive disease. In October 2005, the patient underwent a right hepatic lobectomy and resection of omental nodules. The metastases also presented KIT exon 9 mutation (c.1504_1509dup (p.Ala502_Tyr503dup)). The patient continued medical treatment with imatinib $400 \mathrm{mg}$ /day. Some months later a CT scan showed new peritoneal lesions and the dose of imatinib was increased. The patient came to our attention and was enrolled in a second-line protocol with sunitinib $37.5 \mathrm{mg}$ /day in October 2006 . He received eleven cycles of treatment with good tolerance. In September 2007, a new surgery was conducted with wedge resection of a segment of liver, and excision of nodules in peritoneum and in colon. Sunitinib 37.5 $\mathrm{mg} /$ day was also given and, after two years, a CT scan showed a peritoneal lesion. The patient was then enrolled in a third-line protocol with nilotinib $800 \mathrm{mg} /$ day, but, due to intolerance, treatment was stopped in March 2010. We decided to reintroduce sunitinib $37.5 \mathrm{mg} /$ day. In May 2010, the patient underwent another surgery with the resection of the two macroscopic peritoneal lesions of GIST, but a postoperative CT scan detected another omental metastasis. The patient was continued on sunitinib; however, tolerance started to decline (hand-foot syndrome (grade 3-4 hand-foot syndrome), uncontrolled hypertension). In February 2011, the patient was referred to the Department of Nephrology for the appearance of edema, increase of the serum creatinine up to 1.5 $\mathrm{mg} / \mathrm{dl}$ (eGFR $45.0 \mathrm{ml} / \mathrm{min} / 1.73 \mathrm{~m}^{2}$ ), weight gain (weight was $67.5 \mathrm{~kg}$ ), nephrotic syndrome with proteinuria of $12 \mathrm{~g} / 24 \mathrm{~h}$, dyslipidemia, and hypoalbuminemia. The patient also presented with chest skin rash with multiple vesicular lesions. Blood pressure was 170/100 mm Hg even though he had taken multiple antihypertensive therapies (carvedilol, amlodipine, doxazosin, ramipril, irbesartan, and loop diuretics). Renal ultrasound showed kidneys with normal diameters $(11 \mathrm{~cm})$. Viral and immunological tests were negative. Criocrit was $<1 \%$. Seric immunofixation was positive with detection of monoclonal IgGк; Bence Jones protein research was negative. Urinalysis showed microhematuria and proteinuria $>400 \mathrm{mg} / \mathrm{dl}$, with 24 -hour protein excretion of $12.0 \mathrm{~g} /$ day (glomerular nonselective proteinuria).

A kidney biopsy showed an immunocomplex glomerulonephritis characterized by nodular lesions; in particular, on light microscopy, there was a thickening of the capillary wall and the presence of some deposits (fig. 1a); on immunofluorescence, there were large granular deposits of immunoglobulins and complement (fig. 1b). Oral steroids (prednisone $25 \mathrm{mg} /$ day and subsequent decrease), diuretics, and angiotensin receptor blockers (ARBs) were started. 
In the following months, the serum creatinine increased up to 2.2-2.4 mg/dl (eGFR 27.5 $\mathrm{ml} / \mathrm{min} / 1.73 \mathrm{~m}^{2}$ ), blood pressure control continued to be poor, and there was a persistence of edema and nephrotic syndrome with proteinuria of $8 \mathrm{~g} / \mathrm{day}$. With the hypothesis that the nephrotic syndrome was induced by sunitinib, this therapy was temporarily discontinued and oral steroid therapy was progressively reduced. We observed a subsequent reduction of proteinuria ( $4 \mathrm{~g} / \mathrm{day})$, regression of skin lesions, improvement in blood pressure control, and weight decrease (weight was $60.5 \mathrm{~kg})$.

In November 2011, radiological progression of peritoneal metastasis was found and sunitinib was restarted at the minimum dose (25 $\mathrm{mg} /$ day).

In September 2012, for progressive disease, we decided to change the treatment in favor of sorafenib (an off-label indication). The clinical condition of the patient is good; there is no edema or hand-foot syndrome, blood pressure is controlled by furosemide and amlodipine, serum creatinine is $2.3 \mathrm{mg} /$ day and proteinuria in urine sample is $600 \mathrm{mg} / \mathrm{dl}$.

\section{Discussion}

In the last ten years, the introduction of selective tyrosine kinase inhibitors (imatinib, sunitinib) has modified the natural history of GIST. Sunitinib is a multitargeted tyrosine kinase inhibitor approved as second line in patients with imatinib resistance or intolerance [5]. Gastrointestinal symptoms, hypertension, fatigue, and hematologic disorders are common adverse events. The kidney damage is likely associated with VEGFR inhibition of sunitinib; in fact, cases of renal damage during anti-VEGF therapy (such as bevacizumab) have been described in the literature [11-13]. Proteinuria generally is the first manifestation of renal damage and often there is also hypertension. The incidence of high-grade proteinuria is about $2.2 \%$ of patients with bevacizumab [13]. Recently the first case reported with GIST treated with sunitinib and sorafenib who developed nephritic syndrome was published [10]. How this damage occurs is not yet clear.

Bevacizumab may induce proteinuria for glomerular damage [13]. The discontinuation of anti-VEGF agent reduces proteinuria, probably because the renal damage is partially reversible $[11,12]$. Multiple mechanisms are hypothesized as causes of glomerular damage. First of all, it is well known that anti-VEGF therapy is not selective. Therefore its action is on the tumor cells but also on the sane cells of the body that have VEGF receptors [11]. VEGF receptors are expressed in every tissue, in particular on the vessels and on the glomerulus, playing an important role in the structure of fenestrated endothelial cells where it contributes to the permeability [11]. Secondly, bevacizumab reduces or causes the suppression of nephrin, a protein with an important role in the construction of the glomerular diaphragm. Thirdly, there is also an alteration of normal interaction between podocytes and endothelial cells that cause an injury like pre-eclapsia. Furthermore, biopsy has often showed glomerular thrombotic microangiopathy (TMA), but there is no direct correlation between quantitation of proteinuria and severity of histology renal lesion. It is possible to find TMA in patients with grade 1-2 proteinuria [12].

Hypertension is a clinical sign secondary to renal toxicity of bevacizumab, as a consequence of the nitric oxide reduction anti-VEGF mediated, with the subsequent vasoconstriction and increase of blood pressure [11,12]. Therefore, the initial treatment of patients with proteinuria and hypertension caused by anti-VEGF therapy 
is angiotensin converting enzyme (ACE) inhibitors or angiotensin-2 receptor antagonist (ARA).

The patient can also have other factors that promote renal damage such as renal cell carcinoma, poor renal reserve, primary hypertension, or diabetic nephropathy. In our patient's case, sunitinib was administrated for about 56 months overall and for 25 months continuously. So, the duration of treatment with sunitinib was much longer than the duration in the clinical trial. It is probable that the side effects occurring in our patient may be justified by the long period of the drug administration. Early discontinuation of the medical treatment can limit the damage and often these side effects are completely or partially reversible $[8,9]$. However, since the antitumor activity of this tyrosine kinase inhibitor is cytostatic and not cytotoxic, the discontinuation of treatment is not recommended. In fact, it has been demonstrated that in the metastatic setting the discontinuation of imatinib led to a progression of disease [14]. Moreover, the cytostatic effect of sunitinib in GIST was described using the functional imaging with FDG PET. In particular, it has been demonstrated that using an intermittent administration, there was an early reduction of standardized uptake value (SUV) uptake after only seven days of sunitinib treatment, an increase of SUV uptake during the treatment-off period, and the reduction of SUV uptake again when the therapy is restarted after a break [15].

As a last consideration, our patient has a GIST with KIT exon 9 mutation and it is well reported that GISTs with this mutation are sensitive to sunitinib; no other drugs are available at this time. Considering all of these data, during the nephrotic syndrome, we decided to temporarily reduce the dose of sunitinib and then to maintain a minimal effective dose in order to minimize hypertension and renal kidney dysfunction. The optimal management of side effects in patients treated with chronic therapy and the maintenance of the efficacy is a big challenge for oncologists.

In conclusion, we describe an unexpected occurrence of a nephrotic syndrome in a patient with metastatic GIST treated with sunitinib. Frequent clinical and laboratory tests that include monitoring of kidney function and blood pressure should be performed for early detection of side effects such as hypertension and kidney dysfunction in patients treated for a long time. Moreover, a clinical collaboration between oncologists and nephrologists could also be useful in order to optimize the management of sunitinib.

\section{Disclosure Statement}

The authors have no conflicts of interest to declare in connection with this paper. 

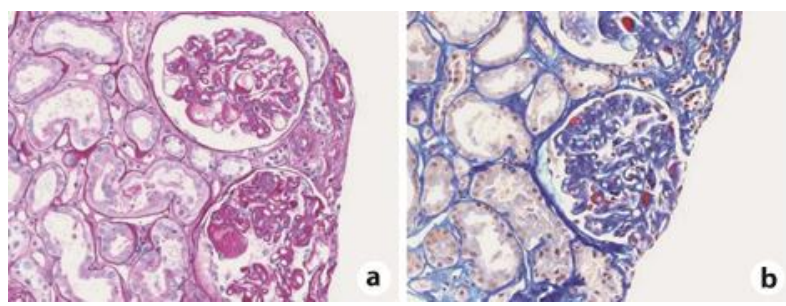

Fig. 1. A kidney biopsy showed an immunocomplex glomerulonephritis characterized by nodular lesions. a On light microscopy there was a thickening of capillary wall and the presence of some deposits. b On immunofluorescence there were big granular deposits of immunoglobulins and complement.

\section{References}

1 Corless CL, Fletcher JA, Heinrich MC: Biology of gastrointestinal stromal tumors. J Clin Oncol 2004;22:3813-3825.

-2 Demetri GD, von Mehren M, Blanke CD, Van den Abbeele AD, Eisenberg B, Roberts PJ, Heinrich MC, Tuveson DA, Singer S, Janicek M, Fletcher JA, Silverman SG, Silberman SL, Capdeville R, Kiese B, Peng B, Dimitrijevic S, Druker BJ, Corless C, Fletcher CD, Joensuu H: Efficacy and safety of imatinib mesylate in advanced gastrointestinal stromal tumors. N Engl J Med 2002;347:472-480.

-3 Dematteo RP, Ballman KV, Antonescu CR, Maki RG, Pisters PW, Demetri GD, Blackstein ME, Blanke CD, von Mehren M, Brennan MF, Patel S, McCarter MD, Polikoff JA, Tan BR, Owzar K; American College of Surgeons Oncology Group (ACOSOG) Intergroup Adjuvant GIST Study Team: Adjuvant imatinib mesylate after resection of localised, primary gastrointestinal stromal tumour: a randomised, double-blind, placebo-controlled trial. Lancet 2009;373:1097-1104.

-4 Joensuu H, Eriksson M, Sundby Hall K, Hartmann JT, Pink D, Schütte J, Ramadori G, Hohenberger P, Duyster J, Al-Batran SE, Schlemmer M, Bauer S, Wardelmann E, Sarlomo-Rikala M, Nilsson B, Sihto H, Monge OR, Bono P, Kallio R, Vehtari A, Leinonen M, Alvegård T, Reichardt P: One vs three years of adjuvant imatinib for operable gastrointestinal stromal tumor: a randomized trial. JAMA 2012;307:1265-1272.

-5 Demetri GD, van Oosterom AT, Garrett CR, Blackstein ME, Shah MH, Verweij J, McArthur G, Judson IR, Heinrich MC, Morgan JA, Desai J, Fletcher CD, George S, Bello CL, Huang X, Baum CM, Casali PG: Efficacy and safety of sunitinib in patients with advanced gastrointestinal stromal tumour after failure of imatinib: a randomised controlled trial. Lancet 2006;368:1329-1338.

-6 Blay JY: Pharmacological management of gastrointestinal stromal tumours: an update on the role of sunitinib. Ann Oncol 2010;21:208-215.

7 George S, Blay JY, Casali PG, Le Cesne A, Stephenson P, Deprimo SE, Harmon CS, Law CN, Morgan JA, RayCoquard I, Tassell V, Cohen DP, Demetri GD: Clinical evaluation of continuous daily dosing of sunitinib malate in patients with advanced gastrointestinal stromal tumour after imatinib failure. Eur J Cancer 2009;45:1959-1968.

-8 Takahashi D, Nagahama K, Tsuura Y, Tanaka H, Tamura T: Sunitinib-induced nephrotic syndrome and irreversible renal dysfunction. Clin Exp Nephrol 2012;16:310-315.

$\checkmark 9$ Liu YC, Chang PM, Liu CY, Yang CY, Chen MH, Pan CC, Chen MH: Sunitinib-induced nephrotic syndrome in association with drug response in a patient with Xp11.2 translocation renal cell carcinoma. Jpn J Clin Oncol 2011;41:1277-1281.

10 Turan N, Benekli M, Ozturk SC, Inal S, Memis L, Guz G, Cetin B, Buyukberber S: Sunitinib- and sorafenibinduced nephrotic syndrome in a patient with gastrointestinal stromal tumor. Ann Pharmacother 2012;46:e27.

11 Kelly RJ, Billemont B, Rixe 0: Renal toxicity of targeted therapies. Target Oncol 2009;4:121-133.

12 Izzedine H, Massard C, Spano JP, Goldwasser F, Khayat D, Soria JC: VEGF signalling inhibition-induced proteinuria: mechanisms, significance and management. Eur J Cancer 2010;46:439-448.

13 Wu S, Kim C, Baer L, Zhu X: Bevacizumab increases risk for severe proteinuria in cancer patients. J Am Soc Nephrol 2010;21:1381-1389.

14 Le Cesne A, Ray-Coquard I, Bui BN, Adenis A, Rios M, Bertucci F, Duffaud F, Chevreau C, Cupissol D, Cioffi A, Emile JF, Chabaud S, Pérol D, Blay JY; French Sarcoma Group: Discontinuation of imatinib in patients with advanced gastrointestinal stromal tumours after 3 years of treatment: an open-label multicentre randomised phase 3 trial. Lancet Oncol 2010;11:942-949.

15 van den Abbeele A, Melenevsky Y, de Vries D, Manola J, Dileo P, Tetrault R, Baum C, Badawi R, Demetri G: Imaging kinase target inhibition with SU11248 by FDG-PET in patients (PTS) with imatinib-resistant gastrointestinal stromal tumors (I-R GIST). J Clin Oncol 2005;ASCO Annual Meeting Proceedings Vol 23:16S. 